\title{
Distance between mandibular canal and third molar root among 20-year-old subjects
}

\section{Rytkönen, Kaisa}

2018-09

Rytkönen , K \& Ventä , I 2018 , ' Distance between mandibular canal and third molar root among 20-year-old subjects ' , Clinical Oral Investigations , vol. 22 , no. 7 , pp. 2505-2509 . https://doi.org/10.1007/s

http://hdl.handle.net/10138/304108

https://doi.org/10.1007/s00784-018-2346-9

publishedVersion

Downloaded from Helda, University of Helsinki institutional repository.

This is an electronic reprint of the original article.

This reprint may differ from the original in pagination and typographic detail.

Please cite the original version. 


\title{
Distance between mandibular canal and third molar root among 20-year-old subjects
}

\author{
Kaisa Rytkönen ${ }^{1} \cdot$ Irja Ventä ${ }^{2}$
}

Received: 10 January 2017 / Accepted: 17 January 2018 / Published online: 25 January 2018

(C) Springer-Verlag GmbH Germany, part of Springer Nature 2018

\begin{abstract}
Objectives The aim of the study was to evaluate the proximity of the mandibular third molar (M3) and the inferior alveolar canal (IAC) in a panoramic radiograph of 20-year-old subjects. The specific aim was to assess differences in this proximity over time. Materials and methods Two similar samples of panoramic radiographs taken in a routine oral health examination with 20-year time interval were examined retrospectively and images with both mandibular M3s were included. The material consisted of 300 subjects ( $25 \%$ men, mean age $20.5 \pm 0.6$ years). The radiographic relationship between the mandibular M3 root and the IAC was assessed as follows: the M3 root was either apart from, tangential to, superimposed with, or inferior to the IAC. Differences between frequencies were tested using the chi-squared test.

Results In the combined samples, only $16 \%$ of the M3s located apart from the IAC, $15 \%$ located tangential to, $61 \%$ superimposed with, and $8 \%$ inferior to the IAC. The proportion of the intimate locations had increased during the 20 -year time interval from 79 to $88 \%(P<0.01)$ and especially in females $(P<0.05)$.

Conclusion The vast majority of the mandibular M3s situated very close to the mandibular canal.

Clinical relevance Our results suggest that in the cohort of 20-year-old non-extraction subjects, most of the M3s are possibly at risk for inferior alveolar nerve injury at removal, as judged from the panoramic radiograph, and also the number of such teeth has increased over the 20 -year period.
\end{abstract}

Keywords Molar third · Panoramic radiograph $\cdot$ Inferior alveolar canal $\cdot$ Extraction

\section{Introduction}

Inferior alveolar nerve (IAN) injury is an unusual and unpleasant complication of mandibular third molar (M3) extraction. This injury can lead to different levels of sensory impairment, from pain sensitization to total numbness. Former studies report the incidence of the risk range for reversible nerve injury to be from 0.35 to $6.3 \%$, and for permanent injuries, i.e., those lasting longer than 6 months, less than $1 \%[1-5]$.

Before removing the mandibular M3, the anatomic relationship between the tooth and the inferior alveolar canal (IAC) is evaluated by viewing a patient's panoramic radiograph, which is the most common preoperative radiologic

Irja Ventä

irja.venta@helsinki.fi

1 Municipal Health Center, Helsinki, Finland

2 Department of Oral and Maxillofacial Diseases, Faculty of Medicine, University of Helsinki, P.O. Box 41, FI-00014 Helsinki, Finland examination before extraction. In the literature, radiographic signs in panoramic radiography are addressed to predict IAN injury during mandibular M3 surgery [6]. The most important risk factor is the superimposing of the root and the nerve canal with one of the following features: (1) interruption of the superior cortical line of the IAC, (2) diversion of the canal, or (3) darkening of the root. Also, when at least one of the root tips extends inferiorly to the inferior cortical line of the canal wall, paresthesia occurs significantly more frequently [7]. It is also assumed that when the structures are apart from each other, paresthesia is not likely to occur. Female patients appear to suffer from IAN injury related to M3 removals more often than male patients $[7,8]$, yet some authors state that gender is not significantly associated with IAN injuries $[4,5]$. In addition, female patients are more likely to have contact between mandibular M3 and IAC on cone beam computed tomography (CBCT) when their panoramic radiograph shows an absence of the white cortical line [8].

Overlapping of the mandibular M3 root and IAC plays an important role in nerve injury $[1-4,6,7,9]$. Studies in this 
research area usually comprise patients requiring the removal of one or more mandibular M3s. However, to our knowledge, no previous study has elucidated the relationship between mandibular M3 root and IAC in non-extraction subjects, i.e., those not in a queue for extraction.

The purpose of this study was to examine the radiographic relationship of mandibular M3 and IAC in a non-extraction cohort of 20-year-old subjects. We examined how often the mandibular M3 root is apart from, tangential to, superimposed with, or inferior to the IAC in a panoramic radiograph. The specific aim was to examine two similar samples taken in the years 1982 and 2002 to determine possible changes with time.

\section{Materials and methods}

We conducted a retrospective study of existing panoramic radiographs of two similar samples taken in 1982 (group 1) and in 2002 (group 2). Both of the materials were collected for earlier longitudinal studies of oral health carried out at the Finnish Student Health Service (FSHS) in Helsinki, Finland $[10,11]$. The subjects were not in a queue for extraction of $\mathrm{M} 3 \mathrm{~s}$, hence the term non-extraction, but after the examination, they were given recommendations for all needed dental care including M3s. From the original material, only radiographs with both mandibular M3s were selected for this study to get similar numbers of left- and right-sided teeth. From the group 1, all 137 eligible panoramic radiographs were available for the present study. From the group 2, 163 of the 170 panoramic radiographs with both mandibular M3s were available, as a few radiographs had been sent to attending dentists.

When gathering the materials in 1982 and 2002, every firstyear student at the University of Helsinki was routinely invited to a free oral health examination at the FSHS. Panoramic radiographs were taken as part of normal dental care. Inclusion criteria into the original longitudinal studies were that all firstyear students born in Helsinki in 1961-1962 (group 1) or in 1981-1982 (group 2) and living in Helsinki at the time of the examination were invited. Students came from several faculties.

\section{Imaging and evaluation of images}

In 1982, panoramic radiographs were taken with an Orthopantomograph OP-3 SE (Palomex, Instrumentarium Oy, Tuusula, Finland), and in 2002 with either Planmeca Promax 2D (Helsinki, Finland) or Soredex Cranex (Tuusula, Finland). Film panoramic radiographs of both groups were examined on an illuminated desk by the first author. Both materials were examined twice with a time interval of at least 1 week.

The relationship between the IAC and the mandibular M3 root was investigated in accordance with Szalma et al. [7] and
Nakamori et al. [12], with slightly modified categories. The relationship of the structures was classified as follows: (1) mandibular M3 and IAC are apart ( $\geq 1 \mathrm{~mm}$ ) from each other, (2) the root tip is adjacent to the upper cortical line of the IAC and the structures are seen as tangential, (3) mandibular M3 root and IAC are superimposed as the root tip extends inferiorly to the superior cortical line of the IAC, and (4) mandibular M3 root and IAC are superimposed and the root tip extends inferiorly to the inferior cortical line of the IAC. If the root was not yet completely formed, the distance was measured from the radio-opaque line of the root follicle to the superior cortical line of the IAC. Distances were measured with a ruler when needed, and magnification of images (1.3) was not taken into account. When disagreement arose about the relation of the structures between the first and second reading, the image was evaluated a third time to ascertain the status.

\section{Ethical considerations}

Panoramic radiographs had been taken as part of routine dental care. Exposing patients to $\mathrm{x}$-rays merely to gather study data is not ethically acceptable. The original study was carried out with the ethical approval of the institutional review board of the Finnish Student Health Service in Helsinki, and the students were informed beforehand of their right to refuse to attend the examination.

\section{Statistical methods}

Cohen kappa statistic was used to judge intra-observer agreement. The kappa $(\kappa)$ values were used in accordance with Szalma et al. [7], Nakagawa et al. [8], and Ghaeminia et al. [13] as follows: $\kappa$ value $<0.40$ was considered poor agreement, $0.40-0.59$ fair agreement, $0.60-0.74$ good agreement, and $0.75-1.00$ excellent agreement. $\kappa$ values were calculated from the two readings of the entire material. $\kappa$ value for group 1 was 0.75 and for group 2 it was 0.79 ; both were excellent agreements. Chi-squared statistics were used to test the differences between frequencies among the two groups and among men and women. The level of significance was set at $P<0.05$. The subgroups possibly at risk for nerve injury (tangential, superimposed, and inferior) were analyzed both separately and combined. Excel® spread sheet program (Microsoft Corporation) and PASW® (Predictive Analytics SoftWare, IBM Corporation) were used in calculating the statistics.

\section{Results}

Demographic features of the subjects are shown in Table 1. A total of 600 mandibular M3s were examined in the 300 
Table 1 Demographic features of the subjects in the two groups

\begin{tabular}{llll}
\hline & Invited & Participated & Both M3s \\
\hline Group 1 & 248 & $181(73 \%)^{\mathrm{a}}$ & $137(76 \%)^{\mathrm{b}}$ \\
Men & 85 & 59 & 40 \\
Women & 163 & 122 & 97 \\
Age \pm SD (years) & & & $20.3 \pm 0.6$ \\
Group 2 & 277 & $234(84 \%)^{\mathrm{a}}$ & $163(70 \%)^{\mathrm{b}}$ \\
Men & 68 & 50 & 35 \\
Women & 209 & 184 & 128 \\
Age \pm SD (years) & & & $20.6 \pm 0.6$ \\
\hline
\end{tabular}

M3 mandibular third molar

${ }^{\text {a }}$ Proportion of those invited

${ }^{b}$ Proportion of those who participated

panoramic radiographs. No significant difference between left and right sides emerged, and therefore, the teeth were analyzed together.

The majority of the teeth $(61 \%)$ in both groups combined were superimposed with the nerve canal and an additional $8 \%$ extended below the IAC (Fig. 1). A significant difference between groups 1 and 2 was found in relation to the proportion of M3s apart from the IAC and this proportion was larger in group 1 than in group $2\left(21\right.$ vs. $\left.12 \%, \chi^{2}=10.079, P<0.01\right)$. Correspondingly, the number of teeth in the combined group of tangential, superimposed, and inferior locations had increased during the 20-year time interval from 79 to $88 \%$ $\left(\chi^{2}=10.021, P<0.01\right)$.

When comparing the variables between men and women, significant differences were detected in group 1 but not in group 2 (Table 2). In group 1, mandibular M3s were more often superimposed with the IAC in women compared with men $(P<0.05$; Table 2 horizontal comparisons).

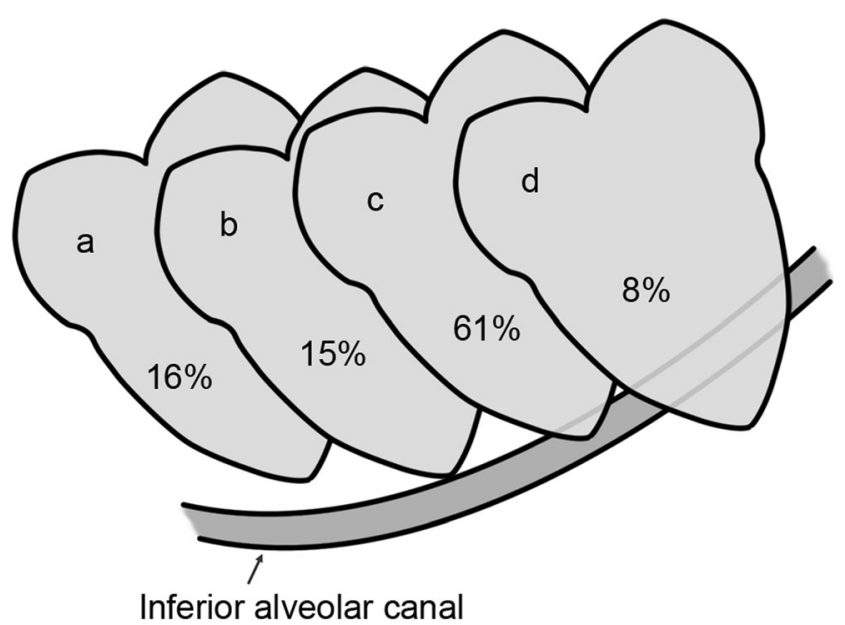

Fig. 1 Distribution of the relationship between mandibular M3 and IAC among 20-year-old subjects (groups 1 and 2 combined, $N=600$ teeth). (a) Apart from, (b) tangential to, (c) superimposed, and (d) inferior to the IAC
Table 2 Comparison of the examined M3 variables in teeth of males and females, and between groups 1 and 2, i.e., at two different time points

\begin{tabular}{llll}
\hline & $\begin{array}{l}\text { Male } \\
n(\%)\end{array}$ & $\begin{array}{l}\text { Female } \\
n(\%)\end{array}$ & $P$ value $\left(\chi^{2}\right)$ \\
\hline Group 1 & $80(100)$ & $194(100)$ & \\
Apart & $22(27)$ & $36(19)^{*}$ & n.s. \\
Tangential & $17(21)$ & $23(12)$ & n.s. \\
Superimposed & $38(48)$ & $118(61)$ & $0.05(4.104)$ \\
Inferior & $3(4)$ & $17(9)$ & n.s. \\
Superimposed/inferior & $41(52)$ & $135(70)$ & $0.01(8.313)$ \\
Tangential/superimposed/inferior & $58(73)$ & $158(81)^{* *}$ & n.s. \\
Group 2 & $70(100)$ & $256(100)$ & \\
Apart & $11(16)$ & $27(11)^{*}$ & n.s. \\
Tangential & $14(20)$ & $37(14)$ & n.s. \\
Superimposed & $41(59)$ & $167(65)$ & n.s. \\
Inferior & $4(6)$ & $25(10)$ & n.s. \\
Superimposed/inferior & $45(64)$ & $192(75)$ & n.s. \\
Tangential/superimposed/inferior & $59(84)$ & $229(89)^{* *}$ & n.s. \\
\hline
\end{tabular}

n.s. not significant

$* P<0.05\left(\chi^{2}=5.826\right) ; * * P<0.05\left(\chi^{2}=5.821\right)$

When comparing the variables between the two groups, i.e., at two different time points, no significant differences were present for teeth of males. However, females had more teeth apart from IAC in group 1 than in group $2(P<0.05$; Table 2 vertical comparisons). Consequently, more teeth of females were in the combined group of tangential, superimposed, and inferior in group 2 than in group $1(P<0.05$; Table 2 vertical comparisons).

\section{Discussion}

Our main result was that in these non-extraction cohorts, most of the mandibular M3s (84\%) were located tangential to, superimposed with, or inferior to IAC and, therefore, were possibly at risk for nerve injury if extracted. In addition, the number of such teeth had increased during the 20 years from 79 to $88 \%$.

In most cases, the panoramic radiograph is the first and only radiograph taken before the removal of M3s. Based on information from the panoramic radiograph and computed tomography (CT) scan and verified during surgery, the IAN was exposed in the socket if the root was superimposed at the lower half or inferiorly to the canal or in the absence of cortication or a periodontal membrane space on a panoramic radiograph [14]. In our study, $69 \%$ of the teeth were superimposed with or inferior to the canal and, therefore, possibly at risk for nerve injury. However, referral of all such subjects to preoperative three-dimensional (3D) scan is not justified. The indications for CBCT are presented in the 
Sedentexct guidelines [15]: "Where conventional radiographs suggest a direct inter-relationship between a mandibular third molar and the mandibular canal, and when a decision to perform surgical removal has been made, CBCT may be indicated." The direct inter-relationship refers to the features presented by Rood and Shehab [6]: darkening of the root, interruption of the canal wall, and diversion of the canal. These inter-relationships were not examined in our study.

Even if the panoramic radiograph shows a close relationship between mandibular M3 and the IAC, there might not be a true anatomic contact between the structures in the $3 \mathrm{D}$ image. In the study of Nakamori et al. [12], a CT image was taken after the evaluation of a close relationship in panoramic radiography. In the CT images, only $40 \%$ of the teeth showed an absence of cortication and true relationship. Similarly, according to Susarla and Dodson [16], 80\% of mandibular M3s were at increased risk for nerve injury after examining the panoramic radiographs. Additional imaging with CT decreased the risk to $33 \%$. However, our study represents subjects not indicated for surgery, and still a similar proportion (84\%) of M3s possibly at increased risk for nerve injury was yielded according to the panoramic radiograph.

The study of Neugebauer et al. [17] showed that the vertical information of the location of the M3 root tip is good in plain radiographs, but horizontal localization is better in CBCT images than in plain films. Therefore, our vertical measurements from panoramic radiographs are anticipated to be reliable. On the other hand, our panoramic radiographs were taken with three different machines which may slightly impact the results. Technical development of machines is fast and it is not possible to use the same machine over 20 years. The proportion of images taken with the last mentioned machine was minimal, as the devices were just exchanging. However, examinations and also clinical decisions are made according to the panoramic radiographs available at each time.

Our results from group 1 showed that female M3s were significantly more often superimposed with or inferior to the canal than male M3s. This result is in accordance with previous results suggesting that female patients suffer from IAN injury more often than male patients [7]. Nevertheless, the findings for group 2 show agreement with other studies indicating that gender has no impact on the relationship between the two structures and no association with the risk of nerve injury $[4,5]$.

Results of our study showed that over 20 years, the anatomy in the M3 region has become more problematic. In female subjects, mandibular M3s seem to be closer to the IAC than before. What lies behind these changes is not easily explained. No previous studies exist comparing the distance between M3s and IAC between cohorts in different decades and verifying our detection. This change towards a more difficult anatomical relationship may not be easily detected in surgical patient samples; however, it could be observed in our nonextraction material examined at two time points. Extraction patterns in our country are assumed to be similar through this time period as most M3s are extracted between 20 and 38 years of age [10]. Although in the 1980s every impacted M3 was indicated for removal, the extractions did not began until after the age of 20 years.

Our cohort was taken from the capital of Finland, and therefore, it may be that subjects born in the capital and studying at the university have higher oral health status than subjects in towns and rural areas. Subjects with higher oral health status presumably have mostly full dentitions. It has been shown that a missing tooth anterior to the M3 substantially enhances the possibilities of eruption, and thus, a third molar may move upwards away from the mandibular canal $[18,19]$. Furthermore, three-fourths of our subjects were women that are known to be good at taking care of their teeth. For these two reasons, the results of our cohort cannot completely be generalized to all people.

A weakness of our study derives from the inclusion criteria of having both mandibular M3s, with only $55 \%$ (group 1) and $59 \%$ (group 2) of invited subjects represented. The number of missing permanent teeth should have also been taken into account. A strength of the study comes from the homogeneity of the cohorts with respect to age, gender, and background. The weakness is also neutralized by the unique design of two similar cohorts with a 20 -year time interval and by the nonextraction characteristics of the subjects. In the literature, it is common to analyze M3s of subjects referred to an oral and maxillofacial unit, and therefore, the samples may include more difficult cases than occurring in the majority of young adults. Our material was collected for longitudinal studies of oral health and not selected to include only subjects in a queue for surgery, and, therefore, represents a neutral cohort.

In summary, the proportion of M3s in a non-extraction population is closer to the mandibular canal than 20 years ago. It may be that subjects with M3s closer to the mandibular canal are at increased risk for nerve injury during M3 extraction, so that an extraction of these M3s should carefully be prepared and carried out.

\section{Compliance with ethical standards}

Conflict of interest The authors declare that they have no conflict of interest.

Informed consent For this type of study, formal consent is not required.

\section{References}

1. Gulicher D, Gerlach KL (2001) Sensory impairment of the lingual and inferior alveolar nerves following removal of impacted mandibular third molars. Int J Oral Maxillofac Surg 30(4):306-312. https://doi.org/10.1054/ijom.2001.0057 
2. Jerjes W, El-Maaytah M, Swinson B, Upile T, Thompson G, Gittelmon S, Baldwin D, Hadi H, Vourvachis M, Abizadeh N, al Khawalde M, Hopper C (2006) Inferior alveolar nerve injury and surgical difficulty prediction in third molar surgery: the role of dental panoramic tomography. J Clin Dent 17(5):122-130

3. Jerjes W, Upile T, Shah P, Nhembe F, Gudka D, Kafas P, McCarthy E, Abbas S, Patel S, Hamdoon Z, Abiola J, Vourvachis M, Kalkani M, al Khawalde M, Leeson R, Banu B, Rob J, el Maaytah M, Hopper C (2010) Risk factors associated with injury to the inferior alveolar and lingual nerves following third molar surgeryrevisited. Oral Surg Oral Med Oral Pathol Oral Radiol Endod 109(3):335-345. https://doi.org/10.1016/j.tripleo.2009.10.010

4. Valmaseda-Castellon E, Berini-Aytes L, Gay-Escoda C (2001) Inferior alveolar nerve damage after lower third molar surgical extraction: a prospective study of 1117 surgical extractions. Oral Surg Oral Med Oral Pathol Oral Radiol Endod 92(4):377-383. https:// doi.org/10.1067/moe.2001.118284

5. Cheung LK, Leung YY, Chow LK, Wong MCM, Chan EKK, Fok YH (2010) Incidence of neurosensory deficits and recovery after lower third molar surgery: a prospective clinical study of 4338 cases. Int J Oral Maxillofac Surg 39(4):320-326. https://doi.org/ 10.1016/j.ijom.2009.11.010

6. Rood JP, Shehab BA (1990) The radiological prediction of inferior alveolar nerve injury during third molar surgery. Br J Oral Maxillofac Surg 28(1):20-25. https://doi.org/10.1016/02664356(90)90005-6

7. Szalma J, Lempel E, Jeges S, Szabó G, Olasz L (2010) The prognostic value of panoramic radiography of inferior alveolar nerve damage after mandibular third molar removal: retrospective study of 400 cases. Oral Surg Oral Med Oral Pathol Oral Radiol Endod 109(2):294-302. https://doi.org/10.1016/j.tripleo.2009.09.023

8. Nakagawa Y, Ishii H, Nomura Y, Watanabe NY, Hoshiba D, Kobayashi K, Ishibashi K (2007) Third molar position: reliability of panoramic radiography. J Oral Maxillofac Surg 65(7):13031308. https://doi.org/10.1016/j.joms.2006.10.028

9. Miloro M, DaBell J (2005) Radiographic proximity of the mandibular third molar to the inferior alveolar canal. Oral Surg Oral Med Oral Pathol Oral Radiol Endod 100(5):545-549. https://doi.org/10. 1016/j.tripleo.2005.03.009

10. Ventä I, Ylipaavalniemi P, Turtola L (2004) Clinical outcome of third molars in adults followed during 18 years. J Oral Maxillofac Surg 62(2):182-185. https://doi.org/10.1016/j.joms.2003.04.011

11. Ventä I, Turtola L (2008) Changes in the oral health of university students during the first three years of studies. Finnish Student
Health Service, Helsinki. http://www.yths.fi/filebank/586-44 SUUN TERVEYDEN MUUTOKSET VENTA-TURTOLA.pdf. Accessed 15 Jan 2018

12. Nakamori K, Fujiwara K, Miyazaki A, Tomihara K, Tsuji M, Nakai M, Michifuri Y, Suzuki R, Komai K, Shimanishi M, Hiratsuka H (2008) Clinical assessment of the relationship between the third molar and the inferior alveolar canal using panoramic images and computed tomography. J Oral Maxillofac Surg 66(11):2308-2313. https://doi.org/10.1016/j.joms.2008.06.042

13. Ghaeminia H, Meijer GJ, Soehardi A, Borstlap WA, Mulder J, Bergé SJ (2009) Position of the impacted third molar in relation to the mandibular canal. Diagnostic accuracy of cone beam computed tomography compared with panoramic radiography. Int $\mathbf{J}$ Oral Maxillofac Surg 38(9):964-971. https://doi.org/10.1016/j. ijom.2009.06.007

14. Maegawa H, Sano K, Kitagawa Y, Ogasawara T, Miyauchi K, Sekine J, Inokuchi T (2003) Preoperative assessment of the relationship between the mandibular third molar and the mandibular canal by axial computed tomography with coronal and sagittal reconstruction. Oral Surg Oral Med Oral Pathol Oral Radiol Endod 96(5):639-646. https://doi.org/10.1016/S1079-2104(03)00356-1

15. European Commission (2012) Radiation protection No 172. Cone beam CT for dental and maxillofacial radiology. Evidence-based guidelines. pp 71-73. http://www.sedentexct.eu/files/radiation protection_172.pdf. Accessed 15 Jan 2018

16. Susarla S, Dodson T (2007) Preoperative computed tomography imaging in the management of impacted mandibular third molars. J Oral Maxillofac Surg 65(1):83-88. https://doi.org/10.1016/j.joms. 2005.10.052

17. Neugebauer J, Shirani R, Mischkowski RA, Ritter L, Scheer M, Keeve E, Zöller JE (2008) Comparison of cone-beam volumetric imaging and combined plain radiographs for localization of the mandibular canal before removal of impacted lower third molars. Oral Surg Oral Med Oral Pathol Oral Radiol Endod 105(5):633642. https://doi.org/10.1016/j.tripleo.2007.08.041

18. Bayram M, Özer M, Arici S (2009) Effects of first molar extraction on third molar angulation and eruption space. Oral Surg Oral Med Oral Pathol Oral Radiol Endod 107(2):e14-e20. https://doi.org/10. 1016/j.tripleo.2008.10.011

19. De-la-Rosa-Gay C, Valmaseda-Castellon E, Gay-Escoda C (2006) Spontaneous third-molar eruption after second-molar extraction in orthodontic patients. Am J Orthod Dentofac Orthop 129(3):337344. https://doi.org/10.1016/j.ajodo.2005.11.002 